\title{
Hormone replacement therapy and female malignancy: what has the Million Women Study added to our knowledge?
}

\section{Jo Marsden}

\section{Introduction}

Breast, ovarian and endometrial cancers account for about one-third of female malignancies diagnosed annually in the UK. Their incidence increases rapidly after puberty and continues to do so until the onset of the menopause, after which rates continue to rise, but not as steeply (Figure 1). ${ }^{1}$ This incidence pattern implicates prolonged endogenous female sex hormone production/exposure in their aetiology and for breast and endometrial cancer is supported by epidemiological evidence. The impact of reproductive factors in the aetiology of ovarian cancer is less clear, but repetitive damage to ovarian epithelium has been hypothesised to predispose to malignant transformation. With all these cancers concern exists about the impact that exposure to hormone replacement therapy (HRT) may have on their incidence and mortality.

The Million Women Study (MWS) is the largest observational study to investigate the association between HRT and female malignancies. Since 2003 several papers, mostly concerning breast cancer, but also endometrial and ovarian cancer, have been published and accompanied by sensationalist journal press releases and media coverage. The resulting stark headlines have undoubtedly contributed to the loss of confidence in HRT by health professionals and the lay public. To be fair, sensationalism surrounding HRT is not exclusive to the MWS; the findings of the contemporaneous Women's Health Initiative (WHI) study in the USA have also been promoted in this way. However, the MWS has significantly influenced recommendations from European advisory committees including the Committee for Safety of Medicines in the UK and resulted in many women receiving suboptimal advice about HRT and a dramatic decline in HRT prescribing. ${ }^{2}$ In view of this it is reasonable to consider the strength of the evidence provided by the MWS and the conclusions made. To do so necessitates review of the MWS in the context of other published clinical evidence to determine what this study has added to available knowledge about HRT, in order to advise perimenopausal and postmenopausal women appropriately.

\section{Background}

The MWS cohort was recruited from women attending the NHS Breast Screening Programme (NHSBSP) between 1996 and 2001. It should be noted that around 70\% of women invited for mammography screening attend, and these women are of higher social class and more likely to be using HRT than those who do not attend. ${ }^{3}$ Of these, again only around $70 \%$ completed the MWS questionnaire. ${ }^{4}$ In practice, therefore, only around $50 \%$ of

J Fam Plann Reprod Health Care 2007; 33(4): 237-243

(Accepted 20 August 2007)

King's Breast Care, Kings College Hospital NHS Foundation Trust, London, UK

Jo Marsden, MD, FRCS(Lond), Consultant Surgeon

Correspondence to: Miss Jo Marsden, King's Breast Care, Kings College NHS Trust, Denmark Hill, London SE5 9RS, UK.

E-mail: jo.marsden@kch.nhs.uk the potentially eligible women are included in the MWS, and they are not representative of the total population.

In total, 1084110 women aged between 50 and 64 years who were invited to attend 66 of the 100 UK breast screening units completed a recruitment questionnaire

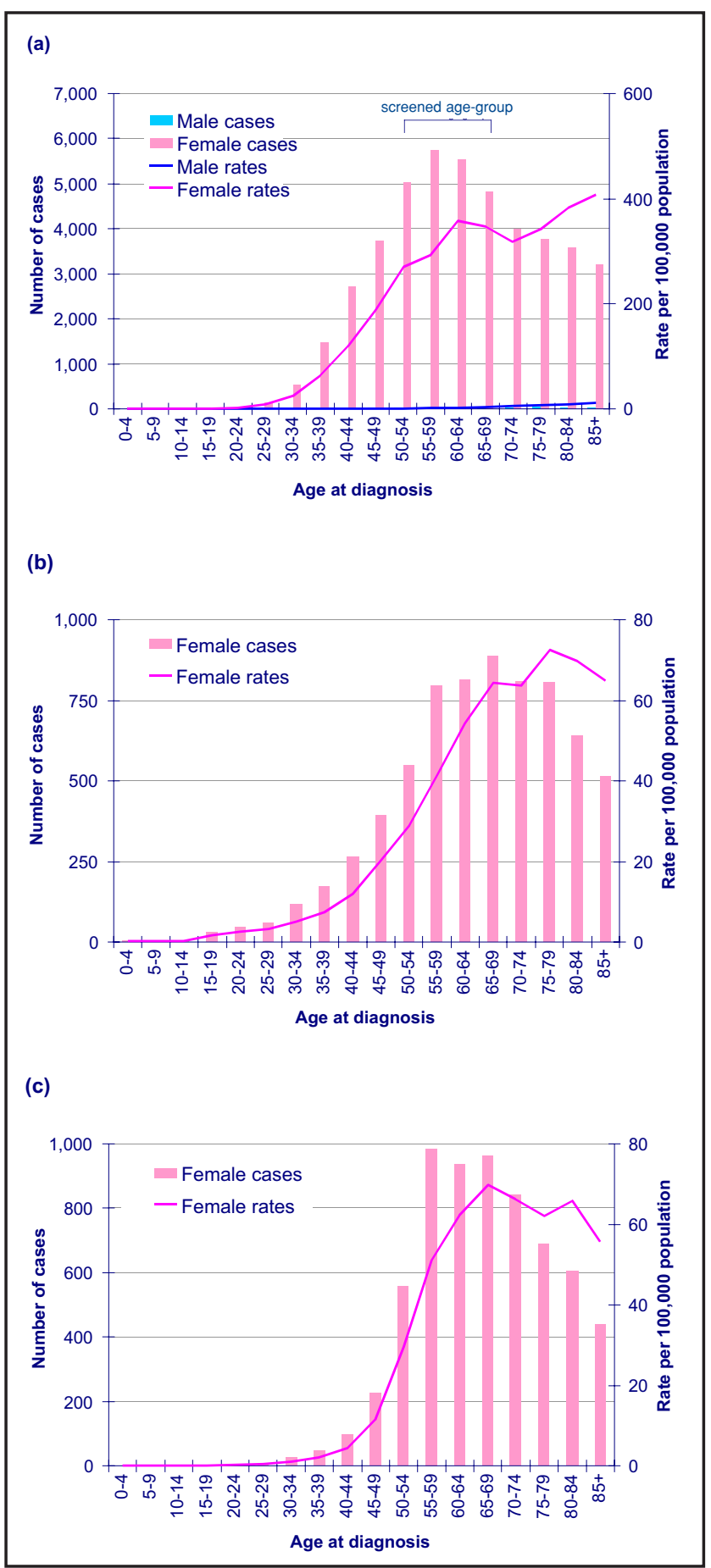

Figure 1 Numbers of new cases and age-specific incidence rates for (a) breast cancer (UK 2004), (b) ovarian cancer (UK 2003) and (c) endometrial cancer (UK 2003). Source: Cancer Research UK1 
Marsden

Table 1 Summary of incidence and mortality findings from the Million Women Study (MWS)

\begin{tabular}{|c|c|c|c|c|c|c|c|}
\hline \multirow[t]{2}{*}{ Cancer type } & \multirow{2}{*}{$\begin{array}{l}\text { Recruitment } \\
\text { questionnaire } \\
\text { data }\end{array}$} & \multirow{2}{*}{$\begin{array}{l}\text { Follow-up } \\
\text { questionnaire } \\
\text { data }\end{array}$} & \multirow{2}{*}{$\begin{array}{l}\text { Average } \\
\text { follow-up } \\
\text { for cancer } \\
\text { diagnosis } \\
\text { (years) }\end{array}$} & \multirow{2}{*}{$\begin{array}{l}\text { Incident } \\
\text { cancers } \\
(n)\end{array}$} & \multirow{2}{*}{$\begin{array}{l}\text { Estimated } \\
\text { mean duration } \\
\text { of HRT } \\
\text { exposure } \\
\text { (years) }\end{array}$} & \multicolumn{2}{|c|}{ Relative risk $(95 \% \mathrm{Cl})$} \\
\hline & & & & & & Incidence & Mortality \\
\hline $\begin{array}{l}\text { Breast }^{a} \\
\text { Current use }\end{array}$ & Yes & No & 2.6 & 9364 & & & \\
\hline All HRT & & & & & 5.8 & $1.66(1.58-1.75)$ & $1.22(1.00-1.48)$ \\
\hline Combined HRT & & & & & - & $2.00(1.88-2.12)$ & - \\
\hline Unopposed HRT & & & & & - & $1.30(1.21-1.40)$ & - \\
\hline Tibolone & & & & & - & $1.45(1.25-1.68)$ & - \\
\hline $\begin{array}{l}\text { Endometriala } \\
\text { Current use }\end{array}$ & Yes & $\begin{array}{l}\text { Yes }(15.5 \% \\
\text { response rate) }\end{array}$ & 3.4 & 1320 & & & \\
\hline Continuous combined & & & & & 5.0 & $0.71(0.56-0.90)$ & - \\
\hline Sequential HRT & & & & & 5.1 & $1.05(0.91-1.22)$ & - \\
\hline Unopposed HRT & & & & & 4.6 & $1.45(1.02-2.06)$ & - \\
\hline Tibolone & & & & & 5.2 & $1.79(1.43-2.25)$ & - \\
\hline $\begin{array}{l}\text { Ovariana } \\
\text { Current use }\end{array}$ & Yes & $\begin{array}{l}\text { Yes ( 66\% } \\
\text { response rate) }\end{array}$ & 5.3 & 2273 & & & \\
\hline All HRT & & & & & 7.7 & $1.20(1.09-1.32)$ & $1.23(1.09-1.38)$ \\
\hline Combined HRT & & & & & 6.9 & $1.14(1.01-1.28)$ & $1.15(1.00-1.33)$ \\
\hline Unopposed HRT & & & & & 9.2 & $1.34(1.13-1.60)$ & $1.48(1.20-1.81)$ \\
\hline 'Other' & & & & & 7.0 & $1.22(0.98-1.53)$ & $1.14(0.87-1.51)$ \\
\hline
\end{tabular}

aRisk unaffected by duration of prior use, time since stopping hormone replacement therapy (HRT) or type of HRT prescribed.

about their lifestyle, socioeconomic background, reproductive and medical history and HRT use. ${ }^{5}$ A second questionnaire was sent to participants between 1999 and 2004 , about 3 years after recruitment, to update the initial information. Based on the recruitment questionnaire data only, the MWS investigators published their findings on the effect of HRT on breast cancer incidence and mortality in 2003, followed by that on the risk of false-positive mammography in 2004. Endometrial and ovarian cancer risk was based on information from both the recruitment and follow-up questionnaires. It can be appreciated, therefore, that although in all instances there was prospective follow-up for cancer outcomes, with the breast cancer findings HRT exposure was not prospective and, as is explained later, has probably led to erroneous conclusions about risk and duration of use.

At the recruitment assessment $50 \%$ of women recorded use of HRT at some time; $33 \%$ were current HRT users with a mean duration of exposure of 5.8 years. Of these, $41 \%$ recorded unopposed oestrogen use, 53\% combined HRT and 6\% 'other' preparations (including tibolone, progestogen alone, androgens and vaginal preparations).5 At the time of publication of the endometrial paper in 2005, follow-up questionnaire data was available for $15.5 \%$ of the cohort. 6 The response rate was two-thirds in 2007 when the ovarian cancer findings were published. ${ }^{7}$

\section{Breast cancer findings of the MWS 8 \\ Diagnosis/incidence}

With an average follow-up of 2.6 years, 9364 breast cancers were diagnosed in 828923 postmenopausal women with an average age of 55.9 years. ${ }^{8}$ The mean time between recruitment questionnaire completion with baseline mammography and cancer diagnosis was 1.2 years. Current use of all HRT types (with an average duration of use of 5.8 years) including tibolone was associated with an increased breast cancer risk, this being greatest with combined therapy (Table 1). Whilst there was evidence for a duration effect for many HRT regimens, risk emerged after periods of exposure of less than 1 to 2 years. Risk was unaffected by the specific oestrogen or progestogen prescribed, pattern of progestogen prescription or route of administration (vaginal preparations were not evaluated) and not elevated in past users. The only factor reported to modify risk was body mass index (BMI), with risk being greater in leaner women (i.e. BMI $<25 \mathrm{~kg} / \mathrm{m}^{2}$, Table 2). A subsequent publication from the MWS has shown an association of HRT with tumours that are hormone sensitive (i.e. oestrogen receptorpositive).$^{9}$

\section{Mortality}

Current HRT users who developed breast cancer were reported to have a higher risk of dying from their disease compared with women without a history of HRT exposure at diagnosis [relative risk (RR) 1.22, 95\% CI 1.00-1.48]. The average time between diagnosis and death was 1.7 years.

\section{Screening mammography}

Current use of any type of HRT was associated with an increased risk of interval cancers (i.e. cancer diagnosed between mammographic screens) and false-positive recall following a screening mammogram (with the exception of tibolone). The latter effect persisted up to 5 years after HRT cessation. ${ }^{10-12}$

\section{Comments}

\section{Breast cancer incidence}

Overall, the patterns of association of HRT with breast cancer incidence reported by the MWS are similar to the body of clinical trial evidence (largely observational) known prior to the publication of their 2003 paper and subsequent to it. Placing the findings in the context of the large placebo-controlled WHI study (i.e. Level I evidence) suggests the MWS probably overestimated the degree of risk attributable to HRT and underestimated the duration of exposure associated with an increase in incidence. ${ }^{13-15}$ The latter is accounted for in that risk estimates were based on information about duration of HRT use at recruitment only. Adding an average of 1.2 years (i.e. the mean time to cancer diagnosis from recruitment) to each of the duration categories presented shifts the pattern of emergent risk to one that is more consistent with data from the WHI and other observational studies where risk associated with 
Table 2 Association of current hormone replacement therapy (HRT) use, body mass index (BMI) and risk of breast, endometrial and ovarian cancer; comparison of the Million Women Study (MWS) and Women's Health Initiative (WHI) study findings

\begin{tabular}{|c|c|c|c|c|c|c|c|}
\hline \multirow[t]{2}{*}{ Cancer type } & \multicolumn{5}{|c|}{$\begin{array}{l}\text { MWS } \\
\text { (relative risk, 95\% Cl) }\end{array}$} & \multicolumn{2}{|c|}{$\begin{array}{l}\text { WHI, annualised risk } \\
\text { (hazard ratio, } 95 \% \mathrm{Cl} \text { ) }\end{array}$} \\
\hline & All HRT & $\begin{array}{l}\text { Oestrogen } \\
\text { alone }\end{array}$ & $\begin{array}{l}\text { All combined } \\
\text { HRT }\end{array}$ & $\begin{array}{l}\text { Continuous } \\
\text { combined } \\
\text { HRT }\end{array}$ & $\begin{array}{l}\text { Sequential } \\
\text { HRT }\end{array}$ & Oestrogen alone & $\begin{array}{l}\text { Continuous } \\
\text { combined HRT }\end{array}$ \\
\hline \multicolumn{8}{|l|}{$\begin{array}{l}\text { Breast } \\
\text { BMI category }\end{array}$} \\
\hline $\begin{array}{l}<25 \\
\geq 25 \\
25-29 \\
\geq 30\end{array}$ & $\begin{array}{l}- \\
- \\
- \\
-\end{array}$ & $\begin{array}{l}1.53(1.36-1.71) \\
1.17(1.05-1.29)\end{array}$ & $\begin{array}{l}2.31(2.12-2.53) \\
1.78(1.64-1.94)\end{array}$ & $\begin{array}{l}- \\
-\end{array}$ & $\begin{array}{l}- \\
-\end{array}$ & $\begin{array}{l}0.94(0.49-1.79) \\
\overline{0} \\
0.61(0.37-1.03) \\
0.89(0.63-1.25)\end{array}$ & $\begin{array}{l}1.35(0.86-2.13) \\
- \\
1.40(0.97-2.01) \\
1.08(0.78-1.40)\end{array}$ \\
\hline \multicolumn{8}{|l|}{$\begin{array}{l}\text { Endometrial } \\
\text { BMI category }\end{array}$} \\
\hline $\begin{array}{l}<25 \\
25-29 \\
\geq 30\end{array}$ & $\begin{array}{l}- \\
- \\
-\end{array}$ & $\begin{array}{l}3.10(1.6-6.2) \\
7.00(3.9-12.6) \\
5.10(1.6-15.7)\end{array}$ & $\begin{array}{l}- \\
- \\
-\end{array}$ & $\begin{array}{l}1.80(1.3-2.6) \\
2.60(1.8-3.8) \\
1.30(0.5-3.1)\end{array}$ & $\begin{array}{l}2.5(1.9-3.1) \\
2.7(2.1-3.7) \\
4.8(3.4-6.9)\end{array}$ & $\begin{array}{l}\text { No sign of any } \\
\text { interaction with } \\
\text { BMI }\end{array}$ & $\begin{array}{l}\text { No sign of any } \\
\text { interaction with } \\
\text { BMI }\end{array}$ \\
\hline \multicolumn{8}{|l|}{$\begin{array}{l}\text { Ovarian } \\
\text { BMI category }\end{array}$} \\
\hline $\begin{array}{l}<25 \\
25-29 \\
\geq 30\end{array}$ & $\begin{array}{l}1.14(0.99-1.33) \\
1.28(1.08-1.51) \\
1.11(0.86-1.43)\end{array}$ & $\begin{array}{l}- \\
- \\
-\end{array}$ & $\begin{array}{l}- \\
- \\
-\end{array}$ & $\begin{array}{l}- \\
- \\
-\end{array}$ & $\begin{array}{l}- \\
- \\
-\end{array}$ & $\begin{array}{l}\text { No sign of any } \\
\text { interaction with } \\
\text { BMI }\end{array}$ & $\begin{array}{l}\text { No sign of any } \\
\text { interaction with } \\
\text { BMI }\end{array}$ \\
\hline
\end{tabular}

Risk decreases with increasing BMI for breast and endometrial cancer in women currently using HRT. No clear association for ovarian cancer.

combined therapy begins to emerge after 3 years' exposure. Risk is not elevated with 5 years' exposure to unopposed oestrogen replacement. This is supported by the available MWS follow-up questionnaire data that reported only $8 \%$ of current HRT users stopped taking it per year. ${ }^{7}$

A major criticism of the MWS methodology is the incomplete documentation of lifetime HRT exposure. ${ }^{16}$ When women attended for their first screening mammogram at recruitment only the name of the currently used HRT regimen, the duration of use and total duration of lifetime HRT use was collected. Risk was estimated based on the current HRT regimen assuming the duration of use was the same as a woman's total lifetime exposure. In failing to record information about other HRT products used - women in the UK change (or switch) HRT products on average two to three times in their lifetime ${ }^{17}-$ the MWS investigators cannot with certainty exclude or confirm that the risk associations found are entirely attributable to the currently used named regimens and whether previously used preparations could have a differential impact on risk.

"Substantial increase in breast cancer risk from combination hormone replacement therapy."

"The use of HRT by women aged 50-64 years in the UK over the past decade has resulted in an estimated 20,000 extra breast cancers, of which 15,000 are likely to be associated with oestrogen-progestogen HRT."

These statements feature in press releases issued by The Lancet and Cancer Research UK to accompany publication of the 2003 MWS paper. In concluding that HRT was probably responsible for an extra 20000 breast cancer cases in the UK over the last 10 years, the MWS investigators were guaranteed to raise anxiety and generate headlines. Given that postmenopausal obesity and excess alcohol intake are associated with a greater breast cancer risk than HRT, equally speculative figures could have been produced to place this in context and as such 50000 and at least 16000 extra breast cancers theoretically could be attributed to postmenopausal obesity and excess alcohol intake, respectively, in women aged between 45 and 64 years over the same time period. ${ }^{18}$

\section{Breast cancer mortality}

The $22 \%$ breast cancer mortality increase (albeit of borderline statistical significance) also found its way into accompanying press releases. The reliability of this finding is questionable and contrasts with other clinical trial data. Given the improved survival trends for treated breast cancer, the mortality difference over such a short follow-up time is hard to explain. No information was provided about the phenotype, stage and treatment of incident cancers diagnosed during the study - all of which are necessary in order to interpret the findings. The increased breast cancer deaths in women who used HRT at diagnosis may simply reflect the greater number of breast cancers diagnosed in this cohort. Hormone receptor status (i.e. oestrogen receptor status) is not an independent prognostic indicator for breast cancer, but is associated with a better survival due to the fact that low-grade tumours are more likely to be receptorpositive than high-grade disease. ${ }^{19}$ HRT is associated with oestrogen receptor-positive breast cancer and would be predicted to be so, given outcomes of endocrine chemoprevention and breast cancer treatment trials where response only occurs in hormone-sensitive disease. ${ }^{20}$

\section{HRT and screening mammography}

The MWS finding that HRT increases the risk of interval cancers and false-positive recall is largely in agreement with other observational trials that overall have shown HRT to reduce mammographic sensitivity (ability to detect an abnormality) and specificity (ability to differentiate cancer from non-cancerous change).

Placebo-controlled trial evidence available at the time of the MWS publications does provide further insight into the potential impact of HRT on the accuracy of screening mammography. This evidence has shown that it is probably only combined therapy that results in an increase in mammographic breast density and hence a potential impact on interval cancer rates due to a reduction in sensitivity (increasing the chance of a cancer being missed at a previous screen). ${ }^{13,15,21}$ Only about $25 \%$ of women who use combined therapy actually develop any density increase and when it occurs it is of the order of about a $5 \%$ 
increase. ${ }^{21}$ This effect of combined HRT occurs regardless of the class of progestogen or prescription pattern (i.e. sequential or continuous), becomes apparent within a few weeks of commencement and then plateaus with increasing duration having no further effect.21 The WHI study also found an absolute increase in the risk of a woman having an abnormal mammogram (i.e. likely benign changes but requiring short-term follow-up or changes suspicious for malignancy) of $10 \%$ over the time of follow-up (i.e. 5 years) if allocated to receive combined therapy, compared with those allocated to receive placebo. ${ }^{13,22}$ However, the WHI study reported that density change with combined therapy was not predictive of an abnormal mammogram. ${ }^{22}$ Whilst an increased breast density could lead to an increase in interval cancers due to 'missed' abnormalities at screening, there are no data from randomised trials to provide more reliable estimates of interval cancer rates and the prognostic features of screen-detected versus interval cancers to determine whether this has any impact on breast cancer mortality.

Mammographic density is unaffected by conjugated equine oestrogen (CEE) alone (observational data suggest no or a minimal impact of oestradiol valerate) but CEE use increased the risk of a mammographic abnormality being found in the WHI study. ${ }^{15,21}$ Here this resulted predominantly in a recommendation for short-term followup (i.e. likely benign change) and after 7 years' follow-up the cumulative absolute percentage increase for a mammogram with an abnormality requiring follow-up in the women allocated to receive CEE was $8 \%$. The absence of any impact on mammographic breast density and reduction (albeit not statistically significant) in breast cancer incidence over the 7-year follow-up of the randomised WHI study argues against an increase in interval cancers due to missed cancers or inappropriate reassurance from short-term follow-up.

All women who participated in the WHI study if taking HRT at recruitment had a 'washout' period of 3 months prior to randomisation when HRT was ceased. Baseline assessment from WHI shows the incidence of abnormal mammograms to be the same irrespective of previous HRT use. ${ }^{23}$ This suggests that any effect of even recent prior combined or unopposed oestrogen therapy on mammographic abnormalities is unlikely to persist for a prolonged duration following its cessation.

Placebo-controlled data overall suggest that most women who attend the NHSBSP who are taking HRT are unlikely to develop either density change or a mammographic abnormality if they are using HRT. For women who are recalled for evaluation of what turns out to be benign change (i.e. false-positive follow-up) direct patient surveys show that this does not deter them from continuing with screening. ${ }^{24}$ The evidence quoted by the MWS investigators that contradicts this is a single retrospective study where lower attendances for routine screening were observed in women who had previously been recalled for further assessment following their initial screening mammogram as part of the NHSBSP, the assumption being this was the main determining factor. Patients' views and reasons for nonattendance were not sought. ${ }^{25}$

\section{Endometrial cancer findings from the MWS6 \\ Incidence}

With an average follow-up of 3.4 years, 1320 endometrial cancers were diagnosed in 716738 postmenopausal women. Follow-up questionnaire data were available for only $15.5 \%$ of women at the time that this analysis was performed. Current use of both tibolone and unopposed oestrogen were associated with an increased endometrial cancer incidence (Table 1); this risk appeared to be greatest in women with a lower BMI (i.e. $<30 \mathrm{~kg} / \mathrm{m}^{2}$ ). A duration effect was observed with tibolone as risk began to emerge after 3 years' exposure but no data were provided about risk, duration of use and unopposed oestrogen. Past use of tibolone and oestrogen were not associated with increased risk.

Overall combined HRT had no effect. In the subgroup of women using a continuous combined preparation containing medroxyprogesterone acetate risk was significantly reduced (RR $0.63,95 \%$ CI $0.43-0.93$ ). Risk was also lowered in women using any type of combined therapy if obese (i.e. BMI $>30 \mathrm{~kg} / \mathrm{m}^{2}$ ). Women with a low BMI (i.e. $<25 \mathrm{~kg} / \mathrm{m}^{2}$ ) were at increased risk if they were current users of sequential HRT (RR 1.54, 95\% CI $1.20-1.99)$.

The authors concluded that oestrogen and tibolone increase endometrial cancer risk and that the addition of a progestogen will counteract the adverse effect of oestrogen, the effect being greater the more days every month that a progestogen is used, particularly in obese women. The conclusion of this publication was that combined HRT will cause a greater increase in the total incidence of endometrial and breast cancer compared with oestrogen or tibolone.

\section{Comments}

\section{Endometrial cancer incidence}

Overall, the findings concur with previous clinical (nonrandomised) studies that show unopposed oestrogen increases endometrial cancer risk in a dose- and durationdependent manner and prevention of this by the addition of a progestogen. ${ }^{26,27}$ Prior observational studies have also consistently shown that a progestogen has to be administered for a minimum of 10 days per cycle, or continuously, to reduce the risk of endometrial cancer associated with oestrogen alone. ${ }^{28}$ In contrast to other published evidence, where risk of endometrial cancer is elevated for at least 5 years post-cessation of unopposed oestrogen replacement, the MWS did not report an increase in endometrial cancer risk with past use of oestrogen alone. However, no information about recency of use was provided.

Few data exist on the risk of endometrial cancer in association with tibolone. The UK General Practice Database cohort study reported a significantly increased incidence, but concluded that this was based on 'fragile' data, in that bias and uncontrolled confounding could not be excluded. ${ }^{29}$ The recent conclusion of the THEBES (Tibolone Histology of the Endometrium and Breast Endpoints Study) investigators, namely that tibolone does not induce endometrial cancer, cannot be supported despite being a randomised study and there being no increase in hyperplasia, as the 2-year follow-up is too short and the study underpowered for cancer incidence to be estimated with certainty. 30

The MWS investigators showed a reduction in risk for women using continuous combined HRT with medroxyprogesterone acetate. Given inconsistency from previous studies exploring associations between class of progestogen and risk and the aforementioned incomplete documentation of HRT products and exposure in the MWS, it would seem premature to base prescribing recommendations solely upon this finding.

The relationship between endometrial cancer risk, HRT and obesity had been shown prior to the MWS. In the Newcomb and Trentham-Dietz study, leaner women (i.e. BMI $<25 \mathrm{~kg} / \mathrm{m}^{2}$ ) had a greater risk of endometrial cancer associated with unopposed oestrogen use (RR 1.20,95\% CI 1.14-1.27). ${ }^{31}$ The combined HRT component of the 
Table 3 Absolute risk of breast, endometrial and ovarian cancer with 5 years of current hormone replacement therapy (HRT) exposure; comparison of the Million Women Study (MWS) and Women's Health Initiative (WHI) study findings

\begin{tabular}{|c|c|c|c|c|c|c|c|c|c|c|}
\hline \multirow[t]{3}{*}{ Cancer } & \multicolumn{6}{|l|}{ MWS } & \multicolumn{4}{|l|}{ WHI } \\
\hline & \multicolumn{2}{|l|}{ All HRT } & \multicolumn{2}{|c|}{ Oestrogen alone } & \multicolumn{2}{|c|}{$\begin{array}{l}\text { Continuous combined } \\
\text { HRT }\end{array}$} & \multicolumn{2}{|c|}{ Oestrogen alone } & \multicolumn{2}{|c|}{$\begin{array}{l}\text { Continuous combined } \\
\text { HRT }\end{array}$} \\
\hline & $\begin{array}{l}\text { Relative } \\
\text { risk }\end{array}$ & $\begin{array}{l}\text { Extra } \\
\text { cancers }{ }^{a} \\
(n)\end{array}$ & $\begin{array}{l}\text { Relative } \\
\text { risk }\end{array}$ & $\begin{array}{l}\text { Extra } \\
\text { cancers }{ }^{a} \\
(n)\end{array}$ & $\begin{array}{l}\text { Relative } \\
\text { risk }\end{array}$ & $\begin{array}{l}\text { Extra } \\
\text { cancers }{ }^{a} \\
(n)\end{array}$ & $\begin{array}{l}\text { Relative } \\
\text { risk }\end{array}$ & $\begin{array}{l}\text { Extra } \\
\text { cancers }{ }^{a} \\
(n)\end{array}$ & $\begin{array}{l}\text { Relative } \\
\text { risk }\end{array}$ & $\begin{array}{l}\text { Extra } \\
\text { cancers }{ }^{a} \\
(n)\end{array}$ \\
\hline Breast & - & - & 1.3 & +1.5 & 2.00 & & 0.73 & -4 & 1.26 & +4 \\
\hline Endometrial & - & - & 1.45 & +1.35 & 0.77 & -0.69 & - & - & 0.81 & -0.56 \\
\hline Ovarian & 1.20 & +0.6 & - & - & - & - & - & - & 1.58 & +1.28 \\
\hline
\end{tabular}

aExtra cancers per 1000 women attributable to HRT with 5 years' use.

WHI failed to show any association with BMI, however the number of cancer cases was too small for reliable subgroup analyses to be performed..$^{30}$ In view of the fact that overall the MWS endometrial paper confirmed previously reported evidence, one questions the necessity of issuing a press release, direct quotes from which are shown below.

"Risk of womb cancer varies according to the type of HRT used."

"Certain types of hormone-replacement therapy (HRT) increase a woman's risk of womb cancer while others do not, concludes a study published in this week's issue of THE LANCET."

\section{Ovarian cancer findings from the MWS7 Incidence}

With an average follow-up of 5.3 years, 2273 incident ovarian cancers were diagnosed in 948576 women. Current use of combined (sequential and continuous) and unopposed HRT was associated with an increased risk of ovarian cancer that was duration dependent, risk beginning to emerge after 5 years' exposure (Table 1). Analysis according to histological type showed the increased risk to be restricted to serous epithelial tumours only (RR 1.53, 95\% CI 1.31-1.79). Risk was not increased with past use of HRT, including women who ceased use within the previous 5 years.

\section{Mortality}

Ovarian cancer mortality was increased in women who were current HRT users at the time of last contact (Table 1). A total of 1591 deaths from ovarian cancer were recorded. Overall current HRT use was estimated to result in one extra ovarian cancer per 2500 women who use it for more than 5 years and one extra ovarian cancer death per 3300 women diagnosed with the disease. Based on the prevalence of HRT use between 1991 and 2006, the MWS investigators suggested that 1300 extra ovarian cancers have been caused by HRT over that time and 1000 excess ovarian cancer deaths.

\section{Comments}

\section{Ovarian cancer incidence}

Clinical data on the association between HRT and ovarian cancer has yet to be confirmed. The most recent metaanalysis evaluating incidence (based on 12238 incident cases) estimates the risk to be increased slightly with everuse of both unopposed and combined therapy, and supports an incessant ovulation hypothesis. ${ }^{32}$ No association with any particular histological subtype of epithelial ovarian cancer was found but other individual studies have shown an association with serous, endometrioid and mucinous cell epithelial cancers. ${ }^{32,33}$
The MWS found no increased risk in past HRT users. If it truly is a significant factor in 'causing' ovarian cancer in previous users then HRT exposure, especially in the recent past, would be expected to elevate risk. In the absence of an appropriate randomised control group for comparison, it is not possible to determine whether the observed results reflect HRT use in women predisposed to developing ovarian cancer, or detection bias due to increased surveillance, or a healthy user effect. Only the combined HRT component of the WHI study has reported on ovarian cancer incidence. Here, risk was elevated to a smaller degree than the MWS, but this was not statistically significant. ${ }^{27}$ The unopposed oestrogen component of the randomised WHI study has still to report on the impact on ovarian malignancy.

\section{Ovarian cancer mortality}

"1000 EXTRA OVARIAN CANCER DEATHS DUE TO HRT IN UK SINCE 1991.”

This is the opening statement of The Lancet press release that accompanied the publication of the MWS ovarian cancer findings (reproduced using the same upper-case format). Irresponsible perhaps, as this estimate of cancer deaths due to HRT was not based on data collected during the study, but inferred from estimates of UK HRT use over that time period, without accounting for stage and treatment of cancers over that time. In absolute terms, taking data from the time period of the study itself, one extra ovarian cancer death per 3300 women has been estimated. There is no rationale for the extrapolation back to 1991 and forward to 2005. The increase in mortality from ovarian cancer in women taking HRT may, as for the breast cancer data, simply reflect the fact that more cancers were diagnosed in HRT users compared with non-users. The WHI study found no excess of cancer deaths in either the unopposed oestrogen, or combined HRT components of their randomised trial.

\section{Summary}

The trends in breast, endometrial and ovarian cancer incidence reported by the MWS are broadly similar to previous and subsequently published clinical evidence. The cancer incidence data, when viewed in absolute terms in comparison with the WHI study, support this (Table 3). Although the MWS findings are based on a very large cohort, these are observational data and should be interpreted in the context of other evidence, particularly randomised controlled trials. If differences exist between women attending the NHSBSP and those who do not, and between attendees who agreed or declined to participate in the study, this could bias the reported results. Women who use HRT are also more likely to exhibit health-orientated 
behaviour than non-users and may be offered more health checks in primary care. These differences cannot be accounted for by the MWS design but are important in its interpretation. The size of this study alone is insufficient reason for its findings to be accepted without question. The mortality data are impossible to interpret with accuracy for reasons outlined previously.

If anything, it is the interpretation and emphasis placed on their findings by the MWS investigators that has created confusion and concern. Counselling women about HRT is complex, due to its diverse profile in relation to cancer- and non-cancer-associated outcomes. The MWS investigators constantly stress the former. Despite the fact that all their publications emphasise that individual findings on breast, ovarian and endometrial cancer should not be viewed in isolation, they present their data in complete absence of other clinical evidence on chronic health conditions affected by HRT that have just, if not more, potential for impacting on a woman's overall survival. These include colorectal cancer (where combined therapy has a protective effect), cardiovascular disease (where there is likely to be benefit if HRT is commenced in the perimenopause or within 10 years of the menopause), osteoporosis (again a beneficial impact) and thromboembolic disease (where risk is initially increased). Their arguments, in addition, do not address the issue of symptom relief and quality of life benefits with HRT and are prescriptive to say the least. Any practitioner discussing HRT is (or should be) aware of the complexities in counselling women adequately. Discussion of known risks and benefits, including current areas of uncertainty, would seem to be a more measured and rounded means of providing public health education, but it probably wouldn't stimulate the production of press releases and generate media headlines. This is a shame, as it stifles debate and ignores the fact that most women are pragmatists and quite capable of weighing up health information, even if this information is uncertain. HRT is still the most effective treatment for the relief of oestrogen deficiency symptoms, and for most women who commence HRT for this indication the relatively short-term exposure (i.e. $<5$ years) is unlikely to have an adverse impact on their overall health whilst improving their well-being.

\section{Statements on funding and competing interests}

Funding The author is the principal investigator for the national UK randomised trial of HRT in symptomatic women with early-stage breast cancer and has been sponsored to attend conferences and received speaker's fees from Organon, Orion, Schering, Servier, Solvay Healthcare Ltd and Wyeth. Consultancy fees have been received from Wyeth and Organon and fees for preparation of educational material from Novartis.

Competing interests The author is also on the council of the British Menopause Society and a member of the European Menopause Society.

\section{References}

1 http://info.cancerresearchuk.org [Accessed 15 July 2007]

2 Faber A, Bouvy ML, Loskamp L, van de Berg PB, Egberts TC, de Jong-van den Berg LT. Dramatic change in prescribing of hormone replacement therapy in The Netherlands after publication of the Million Women Study: a follow-up study. $\mathrm{Br} \mathrm{J}$ Clin Pharmacol 2005; 6: 641-647.

3 Banks E, Beral V, Cameron R, Hogg A, Langley N, Barnes I, et al. Comparison of various characteristics of women who do and do not attend for breast cancer screening. Breast Cancer Res 2002, 4: R1

4 Banks E, Beral V, Reeves G, for the Million Women Study Collaborative Group. The Million Women Study: design and characteristics of the study population. Breast Cancer Res 1999; http://breast-cancer-research.com/content/1/1/73 [Accessed 15 July 2007].

5 Million Women Study Collaborators. Patterns of use of hormone replacement therapy in one million women in Britain,
1996-2000. Br J Obstet Gynaecol 2002; 109: 1319-1330.

6 Beral V, Bull D, Reeves G. Endometrial cancer and hormonereplacement therapy in the Million Women Study. Lancet 2005; 365: 1543-1551.

7 Million Women Study Collaborators. Ovarian cancer and hormone replacement therapy in the Million Women Study. Lancet 2007; 369: 1703-1710.

8 Million Women Study Collaborators. Breast cancer and hormone-replacement therapy in the Million Women Study. Lancet 2003; 362: 419-427.

9 Reeves G, Beral V, Green J, Gathani T, Bull D, for the Million Women Study Collaborators. Hormonal therapy for menopause and breast cancer risk by histological type: a cohort study and meta-analysis. Lancet Oncol 2006; 7: 910-918.

10 Beral V, Reeves G, Green J, Gathani T, Bull D, Crossley B. The effect of hormone replacement therapy on breast and other cancers. In: Menopause and Hormone Replacement, Critchley H, Gebbie A, Beral V (eds). London, UK, RCOG Press, 2004; 136-150.

11 Banks E, Reeves G, Beral V, Bull D, Crossley B, Simmonds M, et al. Impact of use of hormone replacement therapy on false positive recall in the NHS breast screening programme: results from the Million Women Study. BMJ 2004; 328: 1291-1292.

12 Banks E, Reeves G, Beral V, Bull D, Crossley B, Simmonds M, et al. Hormone replacement therapy and false positive recall in the Million Women Study: patterns of use, hormonal constituents and consistency of effect. Breast Cancer Res 2005; 8: R8.

13 Chlebowski RT, Hendrix SL, Lander RD, Stefanick ML, Gass M, Lane D, et al., for the Women's Health Initiative Randomised Trial. Influence of estrogen plus progestin on breast cancer and mammography in healthy postmenopausal women. JAMA 2003; 289: 3243-3253.

14 Stefanick ML, Anderson GL, Margolis KL, Hendrix SL, Rodabough RJ, Paskett ED, et al.; WHI Investigators. Effects of conjugated equine estrogens on breast cancer and mammography screening in postmenopausal women with hysterectomy. JAMA 2006; 295: 1647-1657.

15 Anderson GL, Limacher M, Assaf AR, Bassford T, Beresford $\mathrm{SA}$, Black $\mathrm{H}$, et al. Women's Health Initiative Steering Committee. Effects of conjugated equine estrogen in postmenopausal women with hysterectomy: the Women's Health Initiative randomized controlled trial. JAMA 2004; 291: 1701-1712.

16 Whitehead M, Farmer R. The Million Women Study: a critique. Endocrine Rev 2004; 24: 187-193.

17 Bromley SE, de Vries CS, Farmer RD. Utilisation of hormone replacement therapy in the United Kingdom. A descriptive study using the general practice research database. $\mathrm{Br} J$ Obstet Gynaecol 2004; 111: 369-376.

18 Marsden J, A'Hern R. Progestogens and breast cancer risk: the role of hormonal contraceptives and hormone replacement therapy. J Fam Plann Reprod Health Care 2003; 4: 185-187.

19 Anderson WF, Chatterjee N, Erhler WB, Brawley OW. Estrogen receptor breast cancer phenotypes in the Surveillance, Epidemiology, and End Results database. Breast Cancer Res Treat 2002; 76: 27-36.

20 Patel RR, Sharma CG, Jordan VC. Optimizing the antihormonal treatment and prevention of breast cancer. Breast Cancer 2007; 14: 113-122.

21 Greendale GA, Reboussin BA, Sie A, Singh HR, Olson LK, Gatewood $\mathrm{O}$, et al. Effects of estrogen and estrogen-progestin on mammographic parenchymal density. Postmenopausal Estrogen/Progestin Interventions (PEPI) Investigators. Ann Intern Med 1999; 130: 262-269.

22 McTiernan A, Martin CF, Peck JD, Aragaki AK, Chlebowski RT, Pisano ED, et al. Women's Health Initiative Mammogram Density Study Investigators. Estrogen-plus-progestin use and mammographic density in postmenopausal women: Women's Health Initiative randomized trial. J Natl Cancer Inst 2005; 97 : 1366-1376.

23 Anderson GL, Chlebowski RT, Rossouw JE, Rodabough RJ, McTiernan A, Margolis KL, et al. Prior hormone therapy and breast cancer risk in the Women's Health Initiative randomized trial of estrogen plus progestin. Maturitas 2006; 55: 103-115.

24 Ganott MA, Sumkin JH, King JL, Klym AH, Catullo VJ, Cohen $\mathrm{CS}$, et al. Screening mammography: do women prefer a higher recall rate given the possibility of earlier detection of cancer? Radiology 2006; 238: 793-800.

25 McCann J, Stockton D, Godward S. Impact of false positive mammography on subsequent screening attendance and risk of cancer. Breast Cancer Res 2002; 4: R11.

26 Grady D, Gebretsadik T, Kerlikowske K, Ernster V, Petitti D. Hormone replacement therapy and endometrial cancer risk: a meta-analysis. Obstet Gynecol 1995; 85: 304-313. 
27 Anderson GL, Judd HL, Kaunitz AM, Barad DH, Beresford SA, Pettinger $\mathrm{M}$, et al. Women's Health Initiative Investigators. Effects of estrogen plus progestin on gynecologic cancers and associated diagnostic procedures: the Women's Health Initiative randomized trial. JAMA 2003; 290: 1739-1748.

28 Archer DF. The effect of the duration of progestin use on the occurrence of endometrial cancer in postmenopausal women. Menopause 2001; 8: 245-251.

29 de Vries CS, Bromley SE, Thomas H, Farmer RD. Tibolone and endometrial cancer: a cohort and nested case-control study in the UK. Drug Saf 2005; 28: 241-249.

30 Archer DF, Hendrix S, Ferenczy A, Felix J, Chris Gallagher J, Rymer J, et al., for the THEBES Study Group. Tibolone Histology of the Endometrium and Breast Endpoints Study: design of the trial and endometrial histology at baseline in postmenopausal women. Fertil Steril 2007; [Epub 2 June 2007].

31 Newcomb PA, Trentham-Dietz A. Patterns of postmenopausal progestin use with estrogen in relation to endometrial cancer (United States). Cancer Causes Control 2003; 14: 195-201.

32 Greiser CM, Greiser EM, Doren M. Menopausal hormone therapy and risk of ovarian cancer: systematic review and meta-analysis. Hum Reprod Update 2007; [Epub 27 June 2007].

33 Riman T, Dickman PW, Nilsson S, Correia N, Nordlinder H, Magnusson CM, et al. Hormone replacement therapy and the risk of invasive epithelial ovarian cancer in Swedish women. J Natl Cancer Inst 2002; 94: 497-504.

\title{
Abortion is more than a debate about conscientious objection
}

\author{
Jenny Talia
}

There is nothing like reading a Daily Mail article on sex and abortion to motivate you to campaign for justice and equality in this world. ${ }^{1}$ Linked to a story on the reduction in the number of doctors performing abortions, a general practitioner (GP) said he had quit to return to work as a surgeon because he could not bear to sign a GP contract which "forced him to refer women for terminations". I might have bought the paper in France but I do not believe the said GP and I live in the same country, nor indeed that he signed the same contract as me (and thousands of others in the land). For a start, the contraception "additional services" in the new GP contract is entirely voluntary and, in any case, you really only need to have policies on emergency contraception and preconception care to earn the measly two "QOF" points. Second, if a GP signs up to this, it allows for the referral to other practitioners for unplanned pregnancies without compromising one's conscience. So maybe there are other reasons why the aforementioned GP had to quit and work as a surgeon; and before anyone gets libel-happy, I don't doubt my dear colleague is in any way short of competent.

A recent poll by a well-known GP magazine, Pulse, indicates that a quarter of GPs refuse to sign abortion referral forms, one in five do not believe abortion should be legal, and just over half want to reduce the current 24-week legal limit for abortions. Meanwhile, the latest statistics show abortion rates have been rising in England and Wales since 1970; $32 \%$ of women who had an abortion in 2005 had one or more previous abortions, this proportion has risen from $28 \%$ since 1995.3

You could argue that the best way to reduce abortions is to limit the demand by making it more difficult for women, and thus making them think twice before taking risks. Making a decision to have an abortion is difficult enough and going through with one is traumatic. I despair at the efforts that some people go to make it harder for women to exercise their rights to an abortion. I have no desire to argue with those who have conscientious objections but I fear we are all barking up the wrong tree. No one is celebrating the current rise in abortion rates with glee, not even, dare I

J Fam Plann Reprod Health Care 2007; 33(4): 243

Pastures Green, UK

Jenny Talia, MRCGP, MSc, General Practitioner suggest, the suppliers of abortion services. But is limiting the supply the only answer?

Every unplanned pregnancy that ends in abortion is a failure of health professionals; by this I mean contraception provision in all settings including general practice, community contraceptive clinics and other health services. Of course there are other players too such as schools and parents; I'll get to these another time.

Too much effort is expended on debating the rights and wrongs about abortion and not enough is done to prevent it. What proportion of conscientious objectors makes a conscientious effort to ensure men and women use contraception? Conversely, is the pro-choice contingent too lax about initiating discussions on contraception to men and women opportunistically?

Of course, there is responsibility for everyone along the chain. What I have a problem with are health professionals who not only deny the rights of women for abortion, but also refuse to offer contraception on religious and moral grounds and insist on abstention.

One of the key features of a modern and civil society is the ability to control population growth and fertility. If most of the Western world could do it, what are we doing wrong? Perhaps what it really boils down to is a strong political will, free from religious agenda, to promote better sex education in schools, better access to reliable and free contraception (including condoms) and timely access to abortion, which hopefully by then would be a rare event. This probably explains why the USA fares no better than low-income countries when it comes to fertility control.

Here is my fantasy: young men and women bombarded with sex education messages from primary through to secondary school; similar messages being widely disseminated via magazines, on radio, television soaps and reality programmes; sex education from parents; GPs chasing young adults for chlamydia screening and everyone of reproductive age to give contraceptive advice to earn them QOF points.

Am I asking for something really radical?

References

1 More young doctors oppose abortions on ethical grounds. Daily Mail, 17 April 2007.

2 Good Health viewpoint. Daily Mail, 17 April 2007.

3 Government Statistical Service. Abortion Statistics, England and Wales: 2005 (Statistical Bulletin). London, UK: Department of Health, 2006. http://www.dh.gov.uk/assetRoot/04/13/68/ 59/04136859.pdf [Accessed 15 May 2007]. 